\title{
Los centros regionales en la pugna catalanismo/ anticatalanismo de la Segunda República. El caso de la Casa Regional de Murcia en Barcelona
}

\section{Regional centers in the Catalanism/Anti-Catalanism struggle of the Spanish Second Republic. The case of the Murcia Regional Center in Barcelona}

\author{
Miguel Díaz Sánchez \\ Universitat Autònoma de Barcelona, España \\ miguelds1981@gmail.com \\ https://orcid.org/0000-0003-1896-4732
}

Recibido: 02/04/2021

Aceptado: 06/10/2021

Cómo citar este artículo: DÍAZ SÁNCHEZ, Miguel (2022). Los centros regionales en la pugna catalanismo/anticatalanismo de la Segunda República. El caso de la Casa Regional de Murcia en Barcelona. Pasado y Memoria. Revista de Historia Contemporánea, (24), pp. 189-211, https:// doi.org/10.14198/PASADO2022.24.08

\section{Resumen}

El objetivo del presente trabajo es mostrar el potencial que ofrece el estudio del asociacionismo desarrollado por las distintas colonias de emigrantes en la ciudad de Barcelona durante el periodo republicano. En este caso se ha seleccionado el desplegado por los murcianos a través de la Casa Regional de Murcia. Se analizan las expresiones públicas, la evolución ideológica, las tácticas de persuasión política y los mecanismos de apoyo implementados por esta asociación. La colonia murciana se convirtió en epicentro de varios debates políticos surgidos en una Barcelona azotada por un duro contexto de crisis económica y fuertes confrontaciones sociales, políticas y sindicales. Un contexto que otorga al objeto de análisis de un valor especial para iniciar un camino de investigación aún por desarrollar. 
Palabras clave: Migraciones; Asociacionismo regional; Murcia; Barcelona; España; Segunda República.

\begin{abstract}
The aim of this paper is to present the possibilities offered by the study of the type of associationism developed by the different colonies of migrants in Barcelona during the republican period. In this case, the one deployed by Murcian people through the "Casa Regional de Murcia» has been selected. Public expression, ideological evolution, political persuasion tactics, and support mechanisms implemented by this association are analysed. The Murcian colony became the epicenter of several political debates that emerged in a Barcelona hit by a harsh context of economic crisis and strong social, political and trade union confrontations. This context provides the object of analysis with a special value in order to initiate a research path yet to be developed.
\end{abstract}

Keywords: Migrations; Regional Associationism; Murcia; Barcelona; Spain; Second Spanish Republic.

\title{
Introducción
}

Barcelona se constituyó en un foco de atracción para miles de familias durante el primer tercio del siglo XX. Las principales causas podemos ubicarlas en la pujanza de sus sectores secundario y terciario. Los territorios que mayor aporte demográfico proporcionaron a la capital catalana se circunscribieron a la Cataluña rural, las regiones limítrofes de Aragón y Valencia, y finalmente, las provincias de Murcia y Almería en el sudeste peninsular (Oyón; Maldonado; Griful, 2001: 49-87). Esta última migración adquirió consistencia durante los años de la I Guerra Mundial, pero su verdadero vigor comenzó en la década del veinte (Vilà, 1959). Durante dicha década, la pujanza de la minería declinó en esta zona (especialmente en los territorios costeros), y conllevó que muchos trabajadores de esta industria se unieran a una corriente iniciada con anterioridad por los murcianos residentes en la vega agrícola del río Segura. Durante la contienda europea, estos últimos se vieron forzados a reorientar sus migraciones temporales al norte de África debido al bloqueo marítimo que los alemanes impusieron a las colonias francesas, optando en muchos casos por dirigirse al mediodía francés y a Cataluña (Villar et al., 1999: 50). Los factores de atracción hacia este último territorio podemos concretarlos en la política de obras públicas desplegada por la dictadura primorriverista (1923-1930), el auge de la industria en la región metropolitana de Barcelona, y la necesidad de mano de obra en las zonas agrícolas (sustitutoria) y mineras (nula inversión tecnológica) de su hinterland más cercano (Martínez Carrión, 2005). 
Todas las colonias inmigrantes de Barcelona (mayoritariamente aragoneses, valencianos y murcianos) desarrollaron un potente tejido asociativo de carácter regional durante el primer tercio del siglo XX. ${ }^{1}$ En algunos casos lo hicieron bajo un marcado perfil político, pero salvo contadas excepciones (Martín, 2012), dicho asociacionismo ha carecido de las investigaciones necesarias para su mejor comprensión. Este artículo prestará atención al asociacionismo desplegado por los inmigrantes murcianos durante el periodo republicano, y lo hará a través de su principal valor: la Casa Regional de Murcia en Barcelona (CRM). Para ello analizaremos su expresión pública, su evolución ideológica, sus tácticas de persuasión política y sus mecanismos de apoyo a la comunidad inmigrante que afirmaban representar dentro de un contexto de crisis económica y fuertes confrontaciones sociales, políticas y sindicales (Preston, 2020). Un contexto que situó la problemática de la inmigración en un pedestal privilegiado dentro de la confrontación política acontecida en Cataluña durante el periodo indicado.

\section{La expresión pública de la Casa Regional de Murcia en Barcelona}

Las fuentes hemerográficas y la documentación generada por la propia asociación ofrecen cuantiosa información sobre sus prácticas y discursos públicos. Su análisis debe aplicarse tanto al ámbito catalán como al murciano, ya que la relación de la institución con el territorio de origen no se cerró en ningún momento. Son varios los diarios barceloneses que subjetivaron la inmigración murciana durante estos años (Termes, 1984: 134-154; González, 2004). Uno de ellos fue La Vanguardía, diario que pareció convertirse en el principal altavoz del asociacionismo regional desarrollado en Barcelona, sobre todo en los aspectos relacionados con el ámbito cultural. Bajo un prisma más politizado se situó El Diluvio, un periódico de tendencia federalista que se convirtió en una plataforma propagandística de gran importancia para la comunicación de los actos políticos promovidos por las casas regionales. Frente a dichos diarios se situaron otros como La Publicitat, el semanario Mirador y la revista satírica El Be Negre; todos ellos pertenecientes a un grupo editorial vinculado

1. Para el caso de la colonia murciana constatamos la existencia del Centro Regional Murciano Demócrata (1911), el Centro Provincial Murciano (1913), la Unión Provincial Murciana (1913), el Círculo Provincial Murciano (1917), el Círculo Cartagenero (1924), y el Ateneo Murciano (1929): Archivo Histórico de la Delegación del Gobierno en Cataluña (AHDGC), Fondo de Asociaciones, cajas 307 (exp. 7.689), 348 (exp. 8.942), 422 (exp. 11.830), 479 (exp. 14.011) y 721 (exps. A-226 y A-250). 
al partido político Partit Catalanista Republicà / Acció Catalana Republicana (ACR) (Passarell, 1971; Solà, 1967: 5-7). ${ }^{2}$

Un primer ejemplo del valor de la prensa para el estudio de la CRM lo tenemos con la carta de presentación escrita por su primer presidente: Mariano Lorente Conesa. Gracias a ella podemos observar sus fines inicales:

«hacer un llamamiento a los murcianos residentes en Barcelona con la única finalidad de que obre de revulsivo en la conciencia regional murciana, que tan potente como difusa vegeta en el ambiente cosmopolita de la ciudad [...] en su convivencia con los catalanes, aprendieron de ellos, sin duda, lo que tienen de más característico, su espíritu de asociación y de defensa». ${ }^{3}$

Las fuentes hemerográficas también nos señalan las prácticas y mecanismos de defensa desplegados por la institución. El primer conflicto que involucró de lleno a la CRM en la defensa de la comunidad murciana fue provocado por el Be Negre. Mediante una sátira que definió a los murcianos como poco proclives al trabajo, colocó las siguientes palabras en boca de uno de ellos para categorizarlos políticamente de cara a sus lectores:

«Nosotros, que abandonando la bella huerta murciana venimos a Barcelona [...] nos encontramos en que aquí, como en Murcia, para vivir hay que trabajar. Para eso, no valía la pena de habernos movido. Si no se nos guarda la amable hospitalidad que se debe a los forasteros que tuvieron la desdicha de nacer cansados, gritaremos bien alto!Muera la República!!Muera la Generalidad!!Viva la FAI!». ${ }^{4}$

Este primer envite fue atemperado por El Diluvio, un diario afín de la asociación. ${ }^{5}$ Sin embargo, la contención recomendada se derrumbó tras la publicación

2. ACR fue un partido político de tendencia catalanista y republicana. Fundado en 1922, durante el periodo republicano intentó ocupar una posición de centro para combatir las hegemonías de Esquerra Republicana de Catalunya (ERC) en el centro-izquierda y de la Lliga Regionalista en el centro-derecha. En 1933 sufrió una crisis interna que derivó en la marcha de buena parte de sus fundadores: Antoni Rovira i Virgili y Carles Pi i Sunyer se alistaron en ERC, Manuel Carrasco i Formiguera fundó Unió Democràtica de Catalunya, y Jaume Bofill i Mates regresó a la Lliga Regionalista. Del núcleo fundador solo quedó Lluís Nicolau d'Olwer (firmante del Pacto de San Sebastián y ministro del primer gobierno provisional de la II República), quien a partir de marzo de 1933 reorganizó el partido junto a Amadeu Hurtado (fundador del semanario Mirador) y Claudi Ametlla (Gobernador Civil de Barcelona). Finalmente acabó confluyendo en las alianzas que conformaron la versión catalana del Frente Popular (Molas, 2000: 1-4; Baras, 1984; Ucelay Da Cal, 1982).

3. La Vanguardia de Barcelona, 2-11-1929, p. 9. La carta también fue reproducida en la prensa murciana: El Liberal de Murcia, 13-11-1929, p. 1.

4. El Be Negre, 20-9-1932, p. 1.

5. El Diluvio de Barcelona, 29-9-1932, p. 1. El director del periódico instó a la colonia murciana a no tomar con excesivo agravio las viñetas del semanario satírico. 
de unos artículos de Carles Sentís (1994) en el semanario Mirador. En plena campaña electoral para conformar el primer parlamento democrático catalán (noviembre de 1932), Sentís articuló un discurso que volcó sobre los murcianos las causas de todas las problemáticas actuantes en la Ciudad Condal: mendicidad, delincuencia, venta ambulante, chabolismo y problemas sanitarios (tracoma); mientras que, en el plano político, los vinculó a las tendencias anarcosindicalistas, lerrouxistas y al nacionalismo español más extremista. ${ }^{6}$ Toda esta retahíla de problemáticas no podemos desligarla del principal tema de debate en aquellos momentos: el traspaso de competencias a la Generalitat de Cataluña, y por ende, la cesión de determinadas áreas de gestión que, supuestamente, servirían para paliar dichas problemáticas (educación, sanidad, hacienda, orden público, etc.) $;^{7}$ por esta razón (y para no quedar rezagados), el ala más extremista de ERC también abrazó con gran entusiasmo estos discursos articulados contra la inmigración. ${ }^{8}$

6. Estas retóricas son anteriores a los artículos de Sentís. El trinomio anarquismo - inmigración - murciano ya se había confeccionado como relato dentro del grupo editorial durante la insurrección libertaria del año anterior. Un ejemplo lo tenemos con la interpretación que el prestigioso geógrafo Pau Vila articuló para dotar de una explicación demográfica y cultural a estos sucesos. Lo hizo aludiendo a una antigua civilización de la Edad de Bronce asentada en el sureste peninsular (cultura argárica) para «barbarizar» a los inmigrantes procedentes de dicha zona: La Publicitat de Barcelona, 28-1-1932, p. 1; 9-2-1932, p. 1. Respecto a la identificación con el nacionalismo español más extremista, El Be Negre (2510-1932, p. 3; 1-11-1932, p. 2) fue el medio encargado de hacerlo mediante unas sátiras que situaban todo el potencial electoral de Concentración Española en la inmigración murciana. Concentración Española fue una iniciativa promovida por un reducido grupo de personas que tenían como planteamiento básico «la defensa de los intereses de todos los españoles que viven en Cataluña». Este grupo no se constituyó finalmente en partido para concurrir a las elecciones, pero causó cierto revuelo por su mensaje agresivo: $E l$ Diluvio de Barcelona, 5-10-1932, p. 7; 7-10-1932, p. 1; 9-10-1932, p. 1; 11-10-1932, p. 8; 18-10-1932, p. 9. Un acercamiento a Concentración Española y otros movimientos protofascistas en Barcelona podemos realizarlo en el reciente trabajo de José Fernando Mota (2020). Josep Termes (2011: 427-438) elaboró una visión general de la relación articulada entre la inmigración y el movimiento anarquista.

7. Al crearse una comisión mixta para estudiar los traspasos, los debates se alargaron y el contexto político español y catalán del año 1933 estuvo dominado por esta cuestión (Balcells, 2010: 1.049-1.062).

8. Josep Dencàs (conseller de sanidad por ERC) compareció en rueda de prensa avalando los artículos de Sentis: L'Opinió de Barcelona, 17-2-1933, p. 7. El alcalde de Barcelona, Jaume Aiguadé (ERC), también abrazó sus planteamientos: L'Opinió de Barcelona, 5-2-1933, p. 2. ERC era un partido joven (fundado en 1931) y aglutinador de varias tendencias políticas: tanto Dencàs como Aiguader procedían de Estat Català (Macià), y estaban enfrentados a los que procedían del Partit Republicà Català (Companys), estos últimos con fuerte presencia obrerista (Ucelay Da Cal, 1982). 
Los artículos de Sentís conllevaron un agrio debate de año y medio de duración entre el grupo editorial de ACR y el asociacionismo murciano. Este debate adquirió ciertas connotaciones xenófobas amparadas en las teorías raciales imperantes por aquellos años en toda Europa (Mazower, 2001: 95-124). ${ }^{9}$ La CRM catalogó los artículos como una «campaña contra los murcianos» articulada en «ridículas fantasías», y en una carta confeccionada para trasladar su criterio a las opiniones públicas de Murcia y Cataluña se situó en contra de un discurso que pretendió definirlos como:

«una tribu, una indómita caravana de gitanos, donde la prostitución, la corrupción de menores, el robo, el parricidio y la incivilidad encuentran materia propicia para su desarrollo [...] Tras una serie de ridículas y aparentes investigaciones, se esfuerza en querer sacar como consecuencia que el murciano es incestuoso y muy dada a la promiscuidad la mujer murciana [...] pero en donde rebasa usted el colmo de la mala fe, es al afirmar que entre los murcianos que viven en la Torrassa, se consiente el matrimonio a prueba, o con el consentimiento total y perfecto de los padres y «que lo que abunda más, es la prueba sin matrimonio» y que «mientras estas pruebas tienen lugar entre menores (la mayoría de las veces) los familiares celebran el acto en una habitación contigua con bebidas, juergas y cantos»». ${ }^{10}$

El día anterior a la publicación de esta carta, la prensa murciana ya había referenciado una solicitud que la CRM realizó al Gobierno Civil de Barcelona con el fin de celebrar un mitin en el barrio de La Torrassa (Hospitalet de Llobregat). ${ }^{11}$ Las autoridades permitieron el evento con la condición de eludir los discursos ofensivos contra Cataluña, y la asociación acató su compromiso desplegando proclamas conciliadoras:

«La respuesta de los murcianos a las ofensas que motivan el acto, no debe contestarse por la violencia, pues eso supondría ponerse a la misma altura de quien con toda ausencia de delicadeza, no tiene en cuenta que, con el trabajo

9. Para el caso catalán, esta cuestión fue magníficamente sintetizada por Jordi Nadal (Maluquer, 1965: 9-36; Vandellós, 1985: 5-22).

10. La respuesta fue publicada por El Liberal de Murcia, 18-2-1933, p. 1. Previamente, la entidad había realizado un llamamiento similar en la prensa catalana: La Humanitat de Barcelona, 26-1-1933, p. 3. No podemos obviar la carga despectiva contra la comunidad gitana por parte de la asociación. Por otra parte, también fueron conscientes de quienes eran las principales plumas del grupo editorial vinculado a ACR, ya que instaron a Sentís a la lectura de Vida Privada, una novela de Josep María de Sagarra publicada en 1932. En esta obra, el autor barcelonés denunció los matrimonios concertados que se daban entre la alta sociedad catalana (Sagarra, 1991).

11. El Tiempo de Murcia, 17-2-1933, p. 1. La Torrassa es un barrio de Hospitalet de Llobregat donde residió una importante colonia de inmigrantes murcianos, si bien minoritaria respecto de valencianos y aragoneses (Camos, 1986: 15). 
y el esfuerzo constante de los ofendidos, ha llegado a ser grande y próspera Cataluña hasta colocarse en el puesto necesario para reclamar sus libertades, que encontramos justísimas». ${ }^{12}$

Sin embargo, la prensa conservadora murciana no fue tan conciliadora, y aprovechó la polémica para expandir su anticatalanismo en la sociedad murciana. En este sentido, el diario La Verdad confrontó sus interpretaciones respecto al fenómeno migratorio, y durante esos días publicó varios artículos apelando a la concordia de las regiones españolas, pero con matices que expresaban claramente sus tendencias anticatalanistas:

«No nos toca a nosotros defender esa inmigración y estamos dispuestos a clamar contra ella; pero uniremos nuestra protesta con energía a la que la Casa Regional de Murcia y Albacete en Barcelona formuló ayer ante el presidente de la Generalidad, rechazando las injurias vertidas contra los naturales de nuestra provincia con la vesania de un nacionalismo exaltado del que, por amor a aquellos compatriotas, aunque nos denigran tanto, deseamos verlos curados». ${ }^{13}$

El Tiempo, otro diario de tendencias conservadoras en Murcia, tampoco desaprovechó la ocasión para arremeter contra el estatuto de autonomía catalán, e instó a los catalanes residentes en Murcia a pronunciarse respecto a lo acontecido:

«Ya lo dijimos en ocasión oportuna, que en cuanto se estableciese el Estatuto catalán, muchas regiones y acaso más la nuestra, habrían de sentir los efectos de un nacionalismo exaltado y de una incomprensión lamentable [...] La campaña emprendida en defensa por la Casa Regional Murciana merece el más fervoroso elogio y apoyo. En lo que a nosotros respecta, no solo sentimos toda la indignación que revela su protesta, sino que debemos esperar que en esa protesta y en esa labor de recíproca fraternidad regional, los catalanes que residen entre nosotros, han de colaborar fervorosamente para que se imponga la justicia y el mutuo respeto». ${ }^{14}$

«Como catalanes nos hemos hecho eco del artículo que publica su diario hoy, lamentando se susciten propagandas que solo pueden consentir crear cismas entre regiones hermanas, protestando, como este diario hace, de cuanto se dice ofensivo para Murcia; ignoramos qué fines pueden mover las plumas que tan sin respeto tratan los asuntos de las distintas regiones, como el de la inmigración, que no es problema de solo Barcelona, sino de las grandes poblaciones, no pudiendo atribuir en modo alguno, a los hijos de una región

12. La Vanguardia de Barcelona, 21-2-1933, p. 9. El diario puso en boca de uno de los oradores las palabras citadas.

13. La Verdad de Murcia, 19-2-1933, p. 1.

14. El Tiempo de Murcia, 17-2-1933, p. 1.

Pasado y Memoria. Revista de Historia Contemporánea, 24, 2022, pp. 189-211 
determinada lo que es fruto de todas ellas y aun en ocasiones de los naturales de la región que los lamenta». ${ }^{15}$

Ante semejante polvareda, la defensa de Sentís solo se ciñó a su entorno profesional más cercano. Just Cabot (director de Mirador en aquellas fechas) fue uno de los que defendió el trabajo realizado por el joven periodista. ${ }^{16}$ En este sentido, Cabot centró su atención en los aspectos económicos y demográficos adscritos a la corriente migratoria, pero también avaló el relato articulado respecto a las supuestas problemáticas sociales que los inmigrantes importaban desde sus lugares de origen. ${ }^{17}$ Por otro lado, El Be Negre brindó su particular apoyo con una viñeta que resumió la caracterización de los emigrantes realizada por Sentís. Y seis meses más tarde, el semanario completó su aportación realizando una desafortunada vinculación entre los murcianos y el tracoma:

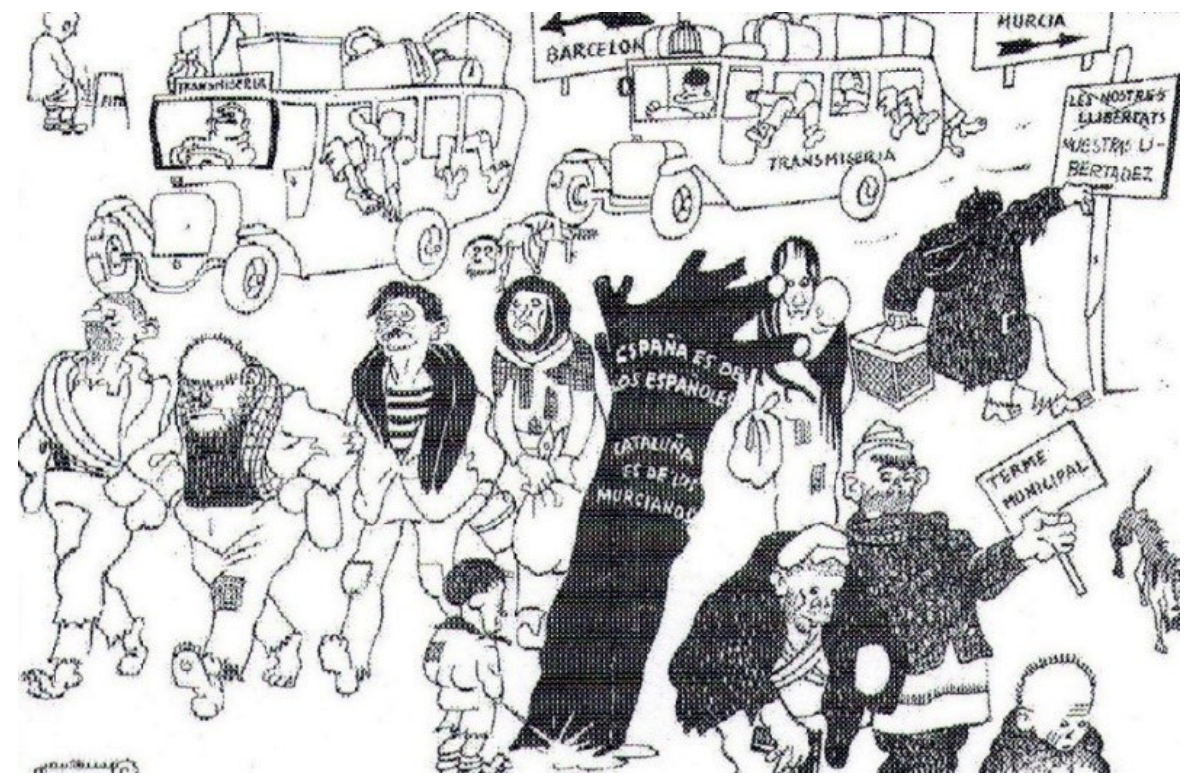

Fuente: El Be Negre, 17-1-1933, p. 1.

15. El Tiempo de Murcia, 18-2-1933, p. 1.

16. Una defensa necesaria para Sentís, ya que según relató en sus memorias fue Cabot quien le propuso realizar este trabajo periodístico (Sentís; Ayen, 2007: 66).

17. Mirador, 26-1-1933, p. 3. 


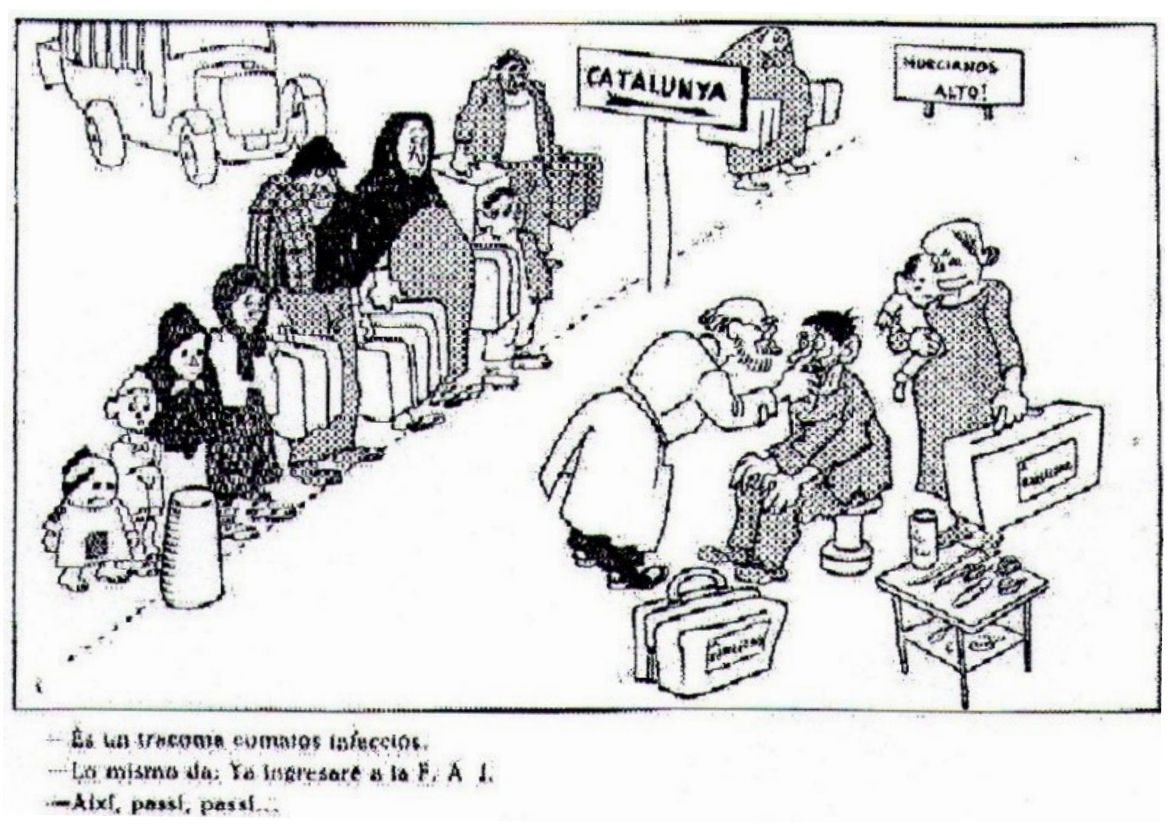

Fuente: El Be Negre, 11-7-1933, p. 4.

Por otra parte, el escritor Josep María de Sagarra también mostró su apoyo incondicional a Sentis:

«Múrcia i els seus homes, les seves dones i les seves criatures, el tracoma, els sensefeina i altres temes semblants, han estat objecte en la nostra època republicana de copiosos, suculents i dissortats comentaris. El joveníssim i estimat amic Carles Sentís va fer, en aquestes mateixes pàgines, uns magnífies reportatges sobre l'emigració murciana que van ésser molt llegits i descubrien punts notables i curiosos del com i el què el murcià arriba a Sans i es dedica a la penetreció pacífica o armada del país». ${ }^{18}$

Además, afirmó que tuvo la oportunidad de observar la miseria reinante en la ciudad de Murcia, y como la violencia de género era una constante entre sus habitantes: «Jo, aquets any, vaig tenir l'ocasió de donar una volta per les terres de Múrcia i d'Almeria. A Múrcia capital, entre altres coses d'importancia, vaig fer una gran amistat amb un canonge de la catedral, i vaig veure una senyora assassinada de frecs pel seu propi marit». ${ }^{19} \mathrm{Y}$ finalmente, también aprovechó

18. Mirador, 10-8-1933, p. 2.

19. Ibid. 
la ocasión para denunciar una supuesta invasión del ámbito cultural catalán menospreciando una poesía escrita en panocho (derivación dialectal del castellano en Murcia) para los Jocs Florals de Badalona:

«El que no s'havia produit encara, en el ram de la cultura murciana importada al nostre país, és un cas d'autèntica poesia murciana que optés a ésser premiada en uns jocs florals catalans [...] Nosaltres trobàvem natural que els murcians s'apoderessin de la Torrassa, del Ninot, del Poble Sec [...] Es possible que els murcians facin això i molt més; el que a mi no se m'hauria acudit mai és que els murcians intentessin apoderar-se dels jocs florals [...] Es clar que en el cas de Badalona no pasarà res, perquè els del jurat no tenim intenció de premiar cap poesia que no sigui catalana, però si els murcians insisteixen tirant als jocs florals, ens podem trobar en el cas d'admetre un bilingüisme poètic murcià-català, cosa que potser tindria conseqüències més transcendentals que el mateix tracoma». ${ }^{20}$

Respecto a la alusión del tracoma, Sagarra siguió la estela abierta por otra de las principales plumas del grupo editorial vinculado a ACR. Nos referimos a Josep Vicenç Foix, quien lo utilizó (metafóricamente) para mostrar su preocupación por lo que la inmigración murciana podía suponer para las esencias lingüísticas y culturales catalanas (Iglésias, 2010; Gómez Inglada, 2010: 11-16; Keown, 2013). Desde su columna de La Publicitat, Foix instó a evitar la «murcianización» del catalán que supuestamente se estaba produciendo en el ámbito educativo, ya que «la tracoma en el catalá parlat i escrit és una senyal de depauperació i de submissió a una raça defallent, tan temible com la fisiológica». ${ }^{21}$

Dentro de este agrio contexto, la CRM optó por encauzar su respuesta mediante la vía institucional. Buscó el amparo de las autoridades murcianas, pero también valoró la posibilidad de trasladar la cuestión al Consejo de Ministros de la República. En las actas de su junta directiva se observa cierta preocupación por las repercusiones que para los murcianos podría acarrear una respuesta contundente por parte de la asociación:

«Se abre debate por la Presidencia afirmando que se debe tener un cuidado especial al tratar este asunto para evitar que pueda derivarse del mismo un estado pasional entre los naturales de las regiones catalana y murciana. El Sr. Carrión dice que ratificando su criterio ya expuesto anteriormente, debe esperarse la comunicación oficial de las autoridades de Murcia relativa a este asunto. El Sr. Vidal asegura que tales campañas en contra de la colonia murciana no tienen importancia y que se debe laborar por la región sin hacer caso de aquellos. El Sr. Garrigós afirma por el contrario que a los murcianos se les

20. Ibid.

21. La Publicitat de Barcelona, 15-12-1932, p. 1. 
insulta por los elementos catalanistas y que los murcianos deben defenderse de tales insultos, tanto más cuando se les niega el trabajo haciéndoles la vida imposible. El Sr. Carrión afirma que esto no tiene nada de extraño por cuanto en Francia no se da trabajo a ningún obrero que no sea del país mientras exista un francés que no trabaje. El Sr. Ortega afirma que las campañas que se vienen haciendo por la prensa catalana tienen importancia y que esta no se debe disimular. Recuerda que es casi seguro que el Orden Público sea concedido a Cataluña por el Estado Central y que si así sucede los murcianos tendríamos que soportar mayores inconvenientes de los que ahora encontramos en esta región. Por ello pide que para precaver esta situación se dirija por esta Casa Regional un respetuoso escrito al presidente del Consejo de Ministros, exponiendo la situación de los murcianos en Cataluña y que además se destaque de la Junta Directiva una comisión que se traslade a Murcia para expresar en aquella capital y en un acto público las vejaciones que los murcianos sufren en la capital catalana. La proposición del Sr. Ortega es rechazada. Se acuerda por último esperar la respuesta oficial de las autoridades murcianas». ${ }^{22}$

La respuesta de las instituciones murcianas solo se ciñó a la realizada por el Ayuntamiento de Murcia. Su pleno municipal constató las quejas de la CRM, pero se desvinculó de la cuestión con el fin de evitar un enfrentamiento institucional, instando a la propia prensa murciana para que se encargara de responder a lo que según ellos:

«solo son diatribas y caricaturas de unos periodistas sin autoridad que no representan a Cataluña, sino al contrario [...] el Ayuntamiento no tiene atribuciones para intervenir oficialmente en este asunto, ya que no afecta solo a los murcianos de este término, sino a los de toda la Región [...] Murcia no ha recibido ninguna ofensa de las autoridades catalanas, y sin duda debería ser la prensa murciana la que protestara de aquella otra prensa». ${ }^{23}$

Al día siguiente, el guante lo recogió el diario La Verdad. El rotativo conservador no dudó en utilizar de coartada esta controversia para expresar su disconformidad con el proceso estatutario catalán, y de paso, mostrar su filosofía conservadora y aporofóbica (Cortina, 2017: 17-21) categorizando a los propios emigrantes murcianos según su estatus social:

«Comprendemos que se atraviesa por una época difícil, en que la economía vacila y acude a remedios heroicos; pero eso no justifica el odio que los persecutores del murciano en Cataluña encienden para ahuyentar a nuestros laboriosos emigrados. Si las medidas de defensa interior se tomaran con ecuanimidad y se hubiese procedido a eliminar los mendigos, los vagos, la gente indeseable que nutre las filas del pistolerismo y de la propaganda disolvente,

22. Archivo de la Casa Regional de Murcia en Barcelona (ACRMB), «Libros de Actas de la Junta Directiva (26-7-1933)».

23. Archivo Histórico Municipal de Murcia, «Actas Capitulares (21-7-1933)».

Pasado y Memoria. Revista de Historia Contemporánea, 24, 2022, pp. 189-211 
lo estimaríamos justo y no levantaríamos nuestra voz en sentido de protesta; pero por lo que estamos viendo, hay en ejecución un plan que lesiona intereses, y eso no lo debemos consentir. Fronteras dentro del territorio español, para atizar odios y acentuar escisiones, creemos que tampoco las debe tolerar el Gobierno. Si al lado de esos murcianos o naturales de otras regiones, que son allí parásitos quizá, hay hombres de espíritu laborioso y sobrio, cuyas virtudes suponen una competencia legítima, a éstos no se les debe considerar como un estorbo». ${ }^{24}$

También fue el diario que con mayor contundencia respondió a las diatribas de Josep Maria de Sagarra (referenciadas anteriormente), convirtiéndose con ello en el rotativo que más interés puso en trasladar esta polémica a la sociedad murciana:

«La profunda antipatía que a un núcleo, al parecer numeroso, de catalanes, se venía incubando, alentada por cierta prensa, toma ya otros derroteros y quiere llegar expresamente a nuestra ciudad con su agresividad violenta [...] El odio adquiere nuevas formas. Creemos que es un medio de cultivo del separatismo: establecer motivos de enemistad entre Cataluña y las demás regiones españolas, a fin de ahondar diferencias y de romper simpatías y de esfumar afinidades [...] Bien quisiéramos responder a estos agravios con un silencio decoroso; pero es pocas veces aconsejable a un periódico callar, cuando se combate lo que a él le importa defender y exaltar, y no nos parece oportuno desertar de unos deberes tan elementales [...] Un escritor llamado José María de Sagarra, del cual dicen que es poeta, quiere tal vez continuar en «Mirador» las acometividades anteriores de Carlos Sentís [...] Estas provocaciones torpes, no deben pasar sin una dura repulsa. No nos extrañaría que con otro espíritu cualquiera se combatiese a Murcia para lucrar una victoria en cualquier batalla de competencias; pero que las fobias las cultive un intelectual, un hombre de letras, parece inaudito [...] no tiene necesidad de decir que Murcia sea un centro de exportación de dinamiteros. La dinamita, por desgracia para ella, y no lo celebramos, ciertamente, ha sido siempre un producto característico de la ciudad condal. Que el señor Sagarra no decline ese honor en la pacífica Murcia».25

\section{La construcción discursiva del «otro» en la dinámica electoral catalana}

Este auge del discurso xenóbofo en el contexto político catalán es recurrente relacionarlo con las vías fascistizantes que atravesaron su espectro nacionalista durante el periodo de entreguerras (Ucelay Da Cal, 1978, 1991, 2005;

24. La Verdad de Murcia, 22-7-1933, p. 1.

25. La Verdad de Murcia, 16-8-1933, p. 1. 
Ealham, 2005). ${ }^{26}$ Nosotros abordaremos esta cuestión a través de la dinámica electoral del periodo republicano, y sostenemos que la introducción de un tema tan sensible en la opinión pública y su traslación a la contienda política, desató unas tensiones que convirtieron a la colonia murciana en una coartada perfecta para la confrontación partidista (Todorov, 2008); más si cabe cuando por primera vez, los partidos de masas compitieron bajo un marco plenamente democrático en España. Esta dinámica conllevó la utilización de la inmigración en las distintas convocatorias electorales, y ACR no dudó en hacerlo con un discurso populista para intentar socavar la hegemonía de ERC dentro del republicanismo catalán. Un terreno que antes de las elecciones municipales de abril de 1931 parecía estarles destinado, pero la irrupción de los segundos con un discurso trasversal (y más populista aún) les dejó sin ninguna opción para ello (Ucelay Da Cal, 1982).

Dentro de esta dinámica competitiva, es necesario referenciar el contexto de crisis económica y sus consecuentes problemas laborales en una ciudad recién convertida en metrópoli europea, donde la inmigración no fue solo una cuestión ligada a los que habían nacido fuera del territorio catalán. Barcelona y su región metropolitana recibieron durante este periodo a una nutrida colonia de inmigrantes procedentes de su entorno rural (la más importante en términos numéricos y porcentuales) que, obviamente, también sufrió las vicisitudes de la crisis económica. Y este hecho los convirtió en objeto apetecido para los partidos vinculados al catalanismo. Dichos partidos intentaron explotar las frustradas aspiraciones de ascenso social de estos migrantes mediante un discurso confeccionado en términos de otredad (Ucelay Da Cal, 1978: 162; Contreras, 1997: 69-82; Oyón, 2008: 359-478) ¿Y cuál fue la comunidad más propicia para diseñar el discurso del «otro» durante el periodo republicano? Obviamente y dentro de los cálculos electorales, la elegida fue la murciana porque en aquellos momentos era la minoritaria entre las más importantes (Arango, 2007: 32).

Los murcianos arribaron a Barcelona en la década anterior bajo una corriente migratoria concentrada en un pequeño espacio de tiempo, lo que los convirtió en una comunidad de individuos perfectamente identificable para el resto de habitantes de la ciudad. A este factor hay que añadir su papel de primera colonia inmigrante con una idiosincrasia que, en cierta medida, difería de los códigos culturales defendidos por el catalanismo más etnocentrista; todo lo contrario de lo que sucedía con aragoneses y valencianos, comunidades con

26. Más aún cuando observamos el itinerario vital, intelectual e ideológico de algunos de los personajes que hemos ido citando a lo largo del texto (Ucelay Da Cal, 1991; Keown, 2013; Vilanova, 2015). 
una larga tradición conjunta de relaciones sociales, culturales y políticas con la sociedad catalana. ${ }^{27}$ En este sentido se articuló la construcción discursiva del «otro» por parte de ACR y su grupo editorial. Un discurso destinado a las clases medias que desertó de las problemáticas laborales (Ucelay Da Cal, 1978: 189-190), ya que como hemos visto, se centró fundamentalmente en referenciar un peligro imaginado para la cultura catalana y el mantenimiento hegemónico del catalanismo político. ${ }^{28}$ Unos temores que utilizaron para presionar en la negociación competencial con el gobierno central, y como arma política contra la propia Generalitat dentro de la dinámica interna catalana. ${ }^{29}$ Por su parte, el devenir de los acontecimientos también sirvió a los sectores conservadores murcianos para fomentar el anticatalanismo entre la sociedad murciana, ejemplificando con ello y a pequeña escala, la tesis de la «retroalimentación agraviativa» sostenida por Ucelay Da Cal (2003: 327-329). En este sentido, el diario La Verdad hizo efectiva su transformación en órgano oficioso de la Confederación Española de Derechas Autónomas (CEDA), y fue el principal medio difusor de estos planteamientos en la región murciana mediante la exaltación continua de la unidad de España (política y religiosa) y la exigencia revocatoria del sistema republicano (Moreno, 1984).

Por su parte, las relaciones entre el asociacionismo murciano y la Generalitat de Catalunya afloraron bajo la égida de las polémicas suscitadas por el grupo editorial vinculado a ACR. Uno de estos acercamientos se produjo con la organización (CRM) de una «semana murciana» en Barcelona. Una actuación que, transcurrido un año, la propia CRM definió como uno de sus grandes logros

27. El concepto de etnocentrismo lo aplicamos como aquel que juzga o valora las otras culturas desde la propia, valorándose el estilo de vida o costumbres del propio grupo como apropiadas, mejores o normales, y las del grupo externo o grupos ajenos como inferiores, extrañas o incorrectas (Malgesini; Giménez, 2000: 169-170).

28. Un discurso que no era nuevo, ya que venía reproduciéndose desde finales del siglo XIX (Ucelay Da Cal, 2003: 289-294). Pero en el caso que nos ocupa, dicho discurso derivó hacia la utilización exclusiva del inmigrante murciano en la confección de los relatos, cuando anteriormente se había acometido mediante la contraposición con lo castellano. Por otra parte, los grupos extremistas del arco nacionalista catalán no concretaron exclusivamente en el inmigrante murciano los males del obrero autóctono. En este sentido solo hemos podido localizar un caso, y de nuevo coincide con la polémica desatada por los artículos de Carles Sentís. Fue el semanario Nosaltres Sols! (18-21933, p. 1), publicación adherida a una organización paramilitar que fue fundada en la década del veinte para hacer frente a la dictadura primorriverista. Durante el periodo republicano se convirtió en una las principales fuerzas de oposición al macianismo, al entender que el líder de ERC colaboraba en exceso con el gobierno central republicano (Molas, 2000: 177-178).

29. Un ejemplo de la utilización política de la inmigración murciana para socavar la labor de la Generalitat: L'Opinió de Barcelona, 3-2-1933, p. 1. 
a la hora de valorar su actuación en la controversia desatada. ${ }^{30}$ La representación política murciana estuvo compuesta por miembros de la Diputación, el Gobierno Civil y el Ayuntamiento de la capital, y fueron recibidos y acompañados en todo momento por el alcalde de Barcelona, Jaume Aiguadé, y por Martí Barrera, diputado en el parlamento de Cataluña y una de las figuras más conciliadoras del organigrama interno de ERC. ${ }^{31}$

Las opiniones despectivas continuaron durante 1934, pero con menos asiduidad y acotadas en los debates que relacionaban el potencial del anarcosindicalismo con la inmigración. Dicho año también observó un decaimiento de las prácticas insurreccionales del anarquismo y la entrada en el gobierno catalán de ACR, por lo que sus retóricas iniciales sobre la inmigración se moderaron sustancialmente. ${ }^{32}$ Los planteamientos xenófobos quedaron confinados al ámbito académico y la ensayística, teniendo una de sus últimas expresiones públicas en el manifiesto «Per la preservació de la raça catalana», donde un grupo de intelectuales encabezados por Josep Antoni Vandellós, Pompeu Fabra y Pau Vila, realizaron un llamamiento para la creación de una sociedad catalana de eugénica. ${ }^{33}$

Es evidente que los artículos de Sentís iban a aderezar la articulación memorialística de la asociación, y la primera evidencia de este proceder se produjo en abril de 1934:

«Un libelo asqueroso y repugnante atacó un día al murcianismo y su baba inmunda cayó manchando a los nuestros de un modo brutal, y fue tal la felonía y ofensa emitida por los conceptos que se nos llegó a imputar por un inculto bárbaro [...] En otras ocasiones habríamos tenido que sufrir la injuria y llorar amargamente la injusticia, pero no ocurrió así: ya teníamos casa, ya éramos unos doscientos cincuenta socios y todo a una sola voz protestamos en la prensa y llegamos más lejos aun dando un mitin en que además de defendernos debidamente, dimos la sensación de que éramos una sociedad constituida que sabía velar por sus derechos». ${ }^{34}$

30. El Liberal de Murcia, 26-4-1933, p. 2.

31. La Vanguardia de Barcelona, 3-5-1933, p. 32; 6-5-1933, p. 5; El Tiempo de Murcia, 30-41933 , p. $3 ; 4-5-1933$, p. $2 ; 6-5-1933$, p. 1 . La primera toma de contacto de la que tenemos constancia es una reunión entre el presidente de la Generalitat (Francesc Macià) y una delegación de la CRM tras la publicación de los artículos de Carles Sentís: La Humanitat de Barcelona, 18-2-1933, p. 1. Bajo esta afinidad debemos contextualizar la respuesta dada por el Ayuntamiento de Murcia al requerimiento realizado por la CRM en julio de 1933 (ver nota 23).

32. A diferencia de Francesc Macià, Lluis Companys si contó con ACR en la confección de sus gobiernos. También acudieron coaligados a las elecciones municipales de enero de 1934 (Molas, 2000: 3).

33. La Publicitat de Barcelona, 12-5-1934, p. 3.

34. El Liberal de Murcia, 26-4-1933, p. 2. 
Básicamente, la acción de la institución durante estos meses fue desmontar los estereotipos articulados por la prensa afín a ACR. Unos estereotipos destinados a conformar la retórica de la alteridad. Sin embargo, la entidad solo construyó una defensa de la identidad murciana basada en la amplificación de lo que internamente potenciaba, o sea, los aspectos cultuales y folclóricos. ${ }^{35}$ En ningún momento desplegó un discurso político externo a la asociación, pero internamente sí actuaron apoyándose en algunas formaciones políticas. Nunca sobrepasaron los encajes institucionales, y todas sus actuaciones estuvieron consensuadas con las instituciones murcianas y catalanas, siendo el Ayuntamiento de Murcia el principal faro para la asociación en este aspecto.

Durante estos años, el Ayuntamiento de Murcia estuvo gobernado por el Partido Socialista Obrero Español (PSOE) y por el Partido Republicano Radical Socialista (PRRS) (Cano, 1985: 323-340). Dichas formaciones también tuvieron aspiraciones estatutarias para la región murciana, aunque sin la potencialidad que, obviamente, se dio en Cataluña. Por lo tanto, nos encontramos ante una influencia política dentro de la CRM que estuvo dominada por tres partidos que mantenían buenas relaciones entre sí, ya que formaban parte de la coalición gubernamental que controlaba el Parlamento español en aquellos momentos: ERC, PSOE, PRRS. ${ }^{36}$

La CRM mostró su adhesión al régimen republicano y su programa político reformista desde su misma proclamación (abril de 1931); ${ }^{37}$ pero también mostró (junto a otros centros regionales adheridos a la Federación de Sociedades Regionales de Barcelona) sus reversas respecto al proceso estatutario catalán, amparándose en consignas vinculadas al lerrouxismo. ${ }^{38} \mathrm{La}$ incapacidad del Partido Republicano Radical (PRR) para ocupar un espacio relevante en Cataluña (Vilanova, 1986) conllevó su continua apelación al voto

35. En este aspecto, la asociación desplegó el itinerario discursivo tradicional en la articulación del relato regionalista murciano (Vilar, 2002: 23-24). Un proceder similar al acontecido en el resto de regionalismos españoles (Archilés, 2006).

36. Son varios los ejemplos de colaboración que se dieron entre estos partidos políticos, incluso dentro la dinámica política catalana (Ucelay - Da Cal, 1978: 174; Cucalón, 2016). Por otra parte, el diputado murciano por el PRRS, Francisco López de Goicoechea, trasladó el apoyo de la sociedad murciana para que Cataluña copara sus aspiraciones autonomistas: La Región de Murcia. Diario de la República, 25-8-1932, p. 7.

37. Las fuentes internas de la asociación hablan de «adhesión proclamada por aclamación» en una Asamblea General de Socios: ACRMB, «Libros de Actas de la Junta Directiva (26-4-1931)».

38. La Publicitat de Barcelona, 28-6-1931, p. 3; La Vanguardia de Barcelona, 28-6-1931, p. 6 . Este hecho creó controversia dentro de la institución, ya que un número importante de socios no estaba de acuerdo con la deriva política adquirida por la Federación desde la proclamación del nuevo régimen republicano: ACRMB, «Libros de Actas de la Junta Directiva (26-4-1931 / 15-5-1931)». 
de las comunidades inmigrantes. ${ }^{39}$ Esta táctica contó con el beneplácito de varios centros regionales ofreciendo capital humano para engrosar sus listas electorales en las elecciones autonómicas de $1932 .{ }^{40}$ No obstante, otros centros regionales (incluido el murciano) intentaron desvincularse de esta operación política. $^{41}$

Los centros regionales no fueron ajenos a la confrontación política acontecida en Cataluña durante el periodo republicano. Cada asociación tenía sus inclinaciones políticas, y sin duda, las de la CRM fueron cercanas al PRRS. A través de las actas de su junta directiva podemos observar cómo mantuvieron una estrecha relación con el director de El Diluvio; $; 2$ y dicho diario, incluso, no dudó en expresar públicamente la importancia de Murcia dentro del federalismo español:

«Los federales murcianos han formado ayer y hoy entre la flor y nata del republicanismo español. Cabalmente en estos dos últimos años el radicalsocialismo de Murcia ha sido una de las fuerzas que con mayor empuje y eficacia han sostenido la política izquierdista del Gobierno republicanosocialista y de las Constituyentes». ${ }^{43}$

A partir de 1934, los contactos de la CRM con el lerrouxismo se intensificaron. Esto se debió al importante peso institucional que el PRR adquirió tras su gran resultado en las elecciones generales de noviembre de 1933 (Townson, 2009).

39. Dentro de las apelaciones generales, las dirigidas a los murcianos se pueden observar en El Diluvio de Barcelona, 17-11-1932, p. 11; 18-11-1932, p. 15. Este proceder del partido de Lerroux fue constante durante el primer tercio del siglo XX (Álvarez Junco, 2011: 246-290).

40. El Diluvio de Barcelona, 8-11-1932, p. 8; 10-11-1932, p. 8; 11-11-1932, p. 16; 17-111932, p. 11. El presidente del centro aragonés tuvo que dimitir para «poder ejercer su libertad dentro de la candidatura radical»: La Publicitat, 15-11-1932, p. 4; El Diluvio de Barcelona, 16-11-1932, p. 8. Los centros andaluz y valenciano sí permitieron figurar en las listas del PRR a miembros de sus juntas directivas: El Diluvio de Barcelona, 5-11-1932, p. 10. Todo esto aconteció por la ausencia de los tradicionales líderes del PRR en tierras catalanas, ya que muchos se trasladaron a otras circunscripciones electorales con mejores perspectivas de cara a las elecciones estatales (Culla, 1986: 454-457).

41. ACRMB, «Libros de Actas de la Junta Directiva (2-11-1932)». Junto al centro murciano, también se desvincularon los centros navarro, asturiano y gallego: La Vanguardia de Barcelona, 18-11-1932, p. 6; El Diluvio de Barcelona, 18-11-1932, p. 9; La Publicitat de Barcelona, 18-11-1932, pp. 2-3.

42. ACRMB, «Libros de Actas de la Junta Directiva (2-8-1933)». El director del diario era Jaime Claramunt (Toll, 2017).

43. El Diluvio de Barcelona, 10-8-1933, p. 1. En las elecciones constituyentes de 1931, el PRRS obtuvo al menos un escaño en las tres circunscripciones de Murcia. Por otra parte, es evidente que estas palabras evocan a la experiencia cantonal murciana de la I República (Pérez Crespo, 1990; Vilar, 1993). 
De igual forma sucedió en los ámbitos más reducidos de Murcia y Cataluña; ${ }^{44}$ en este último caso, el partido de Lerroux copó la gestión de la Generalitat tras la insurrección de su gobierno en octubre de 1934 (Culla, 1986: 457). Pero durante este mismo año, la asociación también comenzó a ofrecer discursos alternativos a su tradición. En este aspecto, observamos como incorporó el obrerismo a sus expresiones públicas, uniéndose al lerrouxismo y al federalismo en este sentido. Sin embargo, esta dinámica está vinculada a una disputa interna acontecida a principios de 1934. Es evidente que la polémica suscitada con el grupo editorial vinculado a ACR supuso un altavoz de notoriedad para la CRM. Hasta ese momento, su presencia en los medios de comunicación había sido inexistente, tanto en Cataluña como en la región murciana. Esta notoriedad influyó en el espectacular incremento de socios registrados por la entidad: $543 \%$ en el año de 1933; y un $720 \%$ para el de $1934 .{ }^{45}$ Es evidente que este incremento desbordó a su junta directiva para mantener la uniformidad ideológica dentro de la institución, y dentro de estas tensiones, varios socios plantearon la posibilidad de escindirse para crear una nueva asociación. ${ }^{46} \mathrm{La}$ motivación ideológica de la fractura está presente en las actas de la junta directiva y en la prensa murciana:

«La colonia murciano-albacetense vivió una época incierta, oscura, sin presente y sin horizontes de mañana, y vivió esos días torpes e injustificados, porque los componentes de la misma no tenían contacto, ni habían sabido formar

44. En Murcia, el PRR obtuvo cuatro de los trece escaños en disputa. La CEDA y el PSOE obtuvieron tres. En este sentido, es evidente que las subvenciones que la asociación recibía de las instituciones murcianas cobraron especial importancia. Son varias las visitas realizadas por alcaldes, diputados, presidentes de la Diputación y gobernadores civiles de Murcia entre 1934 y 1935, y todos ellos con una sustanciosa dotación económica bajo el brazo: Levante Agrario de Murcia, 30-12-1934, p. 1; La Vanguardia de Barcelona, 12-3-1935, p. 7; El Tiempo de Murcia, 26-9-1935, p. 4. La asociación también nombró presidente de honor a Juan José Rocha García, oriundo de Cartagena y ministro de Marina y Estado durante los gobiernos de Alejandro Lerroux: ACRMB, «Libros de Actas de la Junta Directiva (25-2-1935)»; El Tiempo de Murcia, 15-3-1935, p. 2; Levante Agrario de Murcia, 13-4-1935, p. 2. Sin embargo, declinaron ofertas para participar en homenajes propuestos por otros centros regionales a políticos del PRR: ACRMB, «Libros de Actas de la Junta Directiva (24-1-1935)». Junto a otros centros regionales, también se desmarcó de las maniobras ejecutadas por Antonio Royo Villanova (líder del Partido Agrario y paradigma del anticalanismo durante buena parte del primer tercio del siglo XX) para aglutinarlos bajo su égida: La Vanguardia de Barcelona, 1-5-1935, p. 9. Royo Villanova solo consiguió el apoyo de los centros aragonés y castellano: El Diluvio de Barcelona, 17-2-1935, p. 12; 19-2-1935, pp. 7-8.

45. ACRMB, «Libros de registro de socios (1933 y 1934)».

46. De hecho, así lo hicieron registrando una asociación denominada Casa Murciana en el Departamento de Gobernación de la Generalitat de Cataluña (11-2-1934): AHDGC, Fondo Asociaciones, caja 580, exp. 16.816. 
aún el nido que cobija a todos [...] Algunos, arrastrados por otros llegaron un día a cobijarse bajo techumbres de idearios políticos y esa concomitancia que parecía ser un principio de asociación, no tardo en desmembrarse y separar más las voluntades y alejar a los hombres que en aras de su egoísmo, y si se quiere, para que esto sea menos duro, por sus ideologías». ${ }^{47}$

Finalmente, la junta directiva de la entidad se abrió a consensuar las nuevas sensibilidades presentes en la asociación, y durante el segundo semestre de 1934 se produjo el retorno de los socios que habían abandonado la institución. ${ }^{48}$ La negociación se produjo en un contexto político difícil: auge de las fuerzas políticas antirrepublicanas (noviembre de 1933); su ascenso al poder (octubre de 1934); cambio en la presidencia de la Generalitat de Cataluña (enero de 1934); y finalmente, la insurrección acometida por su gobierno y la consecuente suspensión de la autonomía catalana en octubre de 1934. Ante este último acontecimiento, la CRM mostró su apoyo institucional para indultar al jefe de los Mossos d'Esquadra, Enric Pérez Farrás, condenado a muerte por participar en dicha insurrección. ${ }^{49}$ De igual modo, fue el único centro que apoyó a la Casa de Asturias para organizar un festival benéfico en auxilio de las familias mineras que participaron en la insurrección paralela acontecida en esta región. ${ }^{50}$ Por otra parte, constituyó una sección exclusiva para mujeres y abrió la tribuna de opinión de su boletín oficial a todos sus socios. ${ }^{51}$ También permitió organizar actos en su sede social al Socorro Rojo Internacional y a la Confederación Nacional del Trabajo, crear comités de ayuda a los obreros murcianos y participar institucionalmente en homenajes públicos a la figura de Francesc Pi i Margall..$^{52}$ Unos hechos que evidenciarían las buenas relaciones que la asociación mantuvo con el obrerismo y el federalismo político.

Durante los últimos resortes de la II República en paz, la CRM pareció decantarse por los partidos que conformaron el Frente Popular para concurrir a las elecciones generales de febrero de 1936. También permitió una postura más plural dentro de la asociación, donde los elementos ligados al federalismo y el obrerismo pudieron abrir redes de comunicación estables con ERC y los

47. La Verdad de Murcia, 18-7-1934, p. 4.

48. ACRMB, «Libros de Actas de la Junta Directiva 11-7-1934)». Previamente, la Diputación de Murcia había actuado de mediadora en el conflicto: «Ibid. (12-4-1934)». Y en este sentido, también se expresó la publicación mensual de la asociación: La Región Murciana. Boletín mensual de la Casa Regional de Murcia, a. II, n. 13, 1-5-1934, p. 6.

49. La Vanguardia de Barcelona, 14-10-1934, p. 31.

50. ACRMB, «Libros de Actas de la Junta Directiva (9-12-1934)».

51. Ibid. (24-11-1933; 18-8-1934; 12-9-1934).

52. Ibid. (25-11-1934); «Libros de la Comisión de Eventos (14-7-1934)»; El Noticiero de Cartagena, 6-6-1935, p. 1; La Vanguardia de Barcelona, 7-4-1936, p. 8. 
distintos sindicatos. Unas redes que ya existían con anterioridad, pero con la restitución de Companys en la presidencia de la Generalitat (marzo de 1936) y el poder adquirido por el movimiento obrero en Barcelona tras la sublevación militar de julio de 1936, pudieron verse potenciadas y ser utilizadas - entre otras cuestiones - por el asociacionismo murciano para evitar que sus instalaciones fueran incautadas durante la Guerra Civil. ${ }^{53}$

\section{Conclusiones}

La combinación de las fuentes hemerográficas y las generadas por las propias asociaciones, tal y como hemos visto en el caso de la CRM, ofrecen grandes posibilidades para analizar las expresiones públicas, evoluciones ideológicas, tácticas de persuasión política y mecanismos de apoyo individuales y colectivos que el asociacionismo regional desarrolló en Barcelona durante la década del treinta. Hemos constatado cómo este tipo de instituciones no solo se dedicaron a labores de sustento moral y cultural entre sus socios. También funcionaron como plataformas de expresión política a pesar de defender enconadamente el apoliticismo en sus relatos públicos. Y tampoco renunciaron a ejercer algún tipo de influencia política entre sus socios y sobre las colonias migrantes que afirmaban representar. Por otra parte, hemos mostrado que el asociacionismo regional desarrollado en Barcelona durante este periodo sería más variado de lo que tradicionalmente se ha pensado. El estudio de las dinámicas internas de cada institución ayudaría a mejorar la comprensión de esta diversidad, la cual, incluso, estaría condicionada por las dinámicas políticas de los territorios emisores y receptores de migración a las que estarían vinculadas.

\section{Bibliografía}

ÁLVAREZ JUNCO, José (2011). El emperador del Paralelo. Lerroux y la demagogia populista. Barcelona: RBA.

ARANGO, Joaquín (2007). Les primeres migracions del segle XX a Catalunya. Nadala, 41, 18-33.

ARCHILÉS, Ferrán (2006). «Hacer región es hacer patria». La región en el imaginario de la nación española de la Restauración. Ayer, 64, 121-147.

BALCELLS, Albert (dir.) (2011). Història de Catalunya. Barcelona: La Esfera de los Libros.

BARAS, Montserrat (1984). Acció Catalana (1922-1936). Barcelona: Curial.

53. La única referencia de la asociación durante la contienda nos muestra que pareció funcionar con total normalidad, al menos, hasta principios de 1937: La Vanguardia de Barcelona, 17-1-1937, p. 2. 
CAMÓS, Joan (1986). L'Hospitalet la història de tots nosaltres 1930-1936. Barcelona: Diputació de Barcelona.

CANO, José (1985). Alcaldes de Murcia, 1886-1939. Murcia: Ayuntamiento de Murcia.

CONTRERAS, Jesús (1997). El miedo al otro. En Manuel DELGADO (ed.). Ciutat i immigració (69-82). Barcelona: Centre de Cultura Contemporània.

CORTINA, Adela (2017). Aporofobia, el rechazo al pobre. Un desafío para la democracia. Barcelona: Espasa Libros.

CUCALÓN, Diego (2016). De la conspiración al poder. Auge y caída del Partido Republicano Radical Socialista (1929-1934). Tesis doctoral: Universidad de Zaragoza.

CULLÀ, Joan B. (1986). El republicanisme lerrouxista a Catalunya (1901-1923). Barcelona: Curial.

EALHAM, Chris (2005). La lucha por Barcelona. Clase, cultura y conflicto, 18981937. Madrid: Alianza Editorial.

GÓMEZ INGLADA, Pere (2010). Quinze anys de periodisme: les col-laboracions de J.V. Foix a La Publicitat (1922-1936). Barcelona: Institut d'Estudis Catalans.

GONZÁLEZ, Arnau (2004). La immigració vista pel catalanisme (1931-1936). Revista de Catalunya, 193, 9-36.

IGLÉSIAS, Narcís (2010). Llengua i immigració en la Catalunya contemporània. Imaginaris de l'altre i actituds lingüístiques dels parlants arran de la immigració murciana. Els Marges, 92, 18-53.

KEOWN, Dominic (2013). El nacionalisme sospitós de J. V. Foix. En J. LARIOS (ed). La cara fosca de la cultura catalana: la col-laboració amb el feixisme i la Dictadura franquista (75-95), Palma: Lleonard Muntaner.

MALGESINI, Graciela; GIMÉNEZ, Carlos (2000). Guía de conceptos sobre migraciones, racismo e interculturalidad. Madrid: Libros de la Catarata.

MALUQUER, Joaquim (1965). Població i societat a l'àrea catalana. Barcelona: Editorial A.C.

MARTÍN, Alejandro (2012). Movilidad y sociabilidad: asociacionismo migrante aragonés en Barcelona a principios del siglo XX. En Alejandra IBARRA (coord.). No es país para jóvenes. Madrid: Asociación de Historia Contemporánea. [CD].

MARTÍNEZ CARRIÓN, José Miguel (2005). En busca del bienestar: las migraciones en la historia de la Región de Murcia. En Manuel HERNÁNDEZ; Andrés PEDREÑO (coords.). La condición inmigrante: explicaciones e investigaciones desde la Región de Murcia (33-60). Murcia: Universidad de Murcia.

MAZOWER, Mark (2001). La Europa negra. Desde la Gran Guerra hasta la caída del comunismo. Barcelona: Ediciones B.

MORENO, Luis Miguel (1984). La Asociación Católica Nacional de Propagandistas y el diario «La Verdad» de Murcia durante la II República. Anales de Historia Contemporánea de la Universidad de Murcia, 3, 189-213. 
MOLAS, Isidre (ed.) (2000). Diccionari dels partits polítics de Catalunya. Segle XX. Barcelona: Enciclopèdia Catalana.

MOTA, José Fernando (2020). ¡Viva Cataluña española! Historia de la extrema derecha en la Barcelona republicana (1931-1939). Valencia: PUV.

OYÓN, José Luis (2008). La quiebra de la ciudad popular. Espacio urbano, inmigración y anarquismo en la Barcelona de entreguerras, 1914-1936. Barcelona: Ediciones del Serbal.

OYÓN, José Luis; MALDONADO, José: GRIFUL, Eulàlia (2001). Barcelona 1930: un atlas social. Barcelona: Edicions de la UPC.

PASSARELL, Jaume (1971). La Publicitat, diari català. Barcelona: Editorial Pòrtic. PÉREZ CRESPO, Antonio. El cantón murciano. Murcia: Academia Alfonso X el Sabio.

PRESTON, Paul (2020) [1986]. La destrucción de la democracia en España. Reforma, reacción y revolución en la Segunda República. Barcelona: Debolsillo.

SAGARRA, Josep Maria (1991) [1932]. Vida Privada. Barcelona. Cercle de Lectors.

SENTÍS, Carles (1994). Viatge en Transmiserà. Crònica viscula de la primera gran emigració a Catalunya. Barcelona: Edicions La Campana.

SENTÍS, Carles; AYEN, Xavier (2007). Memorias de un espectador. Barcelona: Destino.

SOLÀ, Lluís (1967). El be negre (1931-1936). Barcelona: Editorial Bruguera.

TERMES, Josep (1984). La immigració a Catalunya i altres estudis d'història del nacionalisme català. Barcelona: Editorial Empúries.

TERMES, Josep (2011). Historia del anarquismo en España (1870-1980). Barcelona. RBA.

TODOROV, Tzvetan (2008). El miedo a los bárbaros. Barcelona: Galaxia Gutenberg.

TOLL, Gil (2017). Jaime Claramunt, el cubano que dirigió El Diluvio, Diario Republicano de Barcelona. Revista internacional de Historia de la Comunicación, 8, 25-42. https://doi.org/10.12795/RiHC

TOWNSON, Nigel (2009). ¿Rectificación o reacción? La alianza de centro derecha, 1933-1935. En Manuel BALLARÍN; Diego CUCALÓN; José Luis LEDESMA (coords.). La II República en la encrucijada: el segundo bienio (25-52). Zaragoza: Cortes de Aragón.

UCELAY DA CAL, Enric (1978). La crisi dels nacionalistes radicals catalans (19311932). Recerques: història, economia i cultura, 8, 159-206.

UCELAY DA CAL, Enric (1982). La Catalunya populista. Imatge, cultura i política en l'etapa republicana (1931-1939). Barcelona: La Magrana.

UCELAY DA CAL, Enric (1991). Vanguardia, fascismo y la interacción entre nacionalismo español y catalán: el proyecto catalán de Ernesto Giménez Caballero y algunas ideas corrientes en círculos intelectuales de Barcelona, 1927-1933. En Justo G. BERAMENDI; Ramón MÁIZ (comps.). Los nacionalismos en la España de la II República (39-95). Madrid: Siglo XXI de España Editores. 
UCELAY DA CAL, Enric (2003). El imperialismo catalán. Prat de la Riba, Cambó, D'Ors y la conquista moral de España. Barcelona: Edhasa.

UCELAY DA CAL, Enric (2005). Los «malos de la película»: las Joventuts d'Esquerra Republicana - Estat Català y la problemática de un «fascismo catalán». Ayer, 59, 147-172.

VANDELLÓS, Josep Antoni (1985) [1935]. Catalunya, poble decadent. Barcelona: Edicions 62.

VILÀ, Joan (1959). La aportación murciana al crecimiento poblacional de Barcelona. Anales de la Universidad de Murcia, 17, 89-103.

VILANOVA, Francesc (2015). Fer-se franquista. Guerra Civil y postguerra del periodista Carles Sentís (1936-1946). Barcelona: Lleonard Muntaner Editores.

VILANOVA, Mercè (1986). Atlas electoral de Catalunya durant la Segona República: orientació del vot, participació i abstenció. Barcelona: Edicions de La Magrana.

VILAR, Juan Bautista (1993). El federalismo en los orígenes del Cantón de Cartagena (el Partido Republicano Federal en Murcia y su región, 1868-1873). Anales de Historia Contemporánea, 9, 123-173.

VILAR, Juan Bautista (2002). Murcia: de la emigración a la inmigración. Murcia: Fundación Centro de Estudios e Investigaciones Locales.

VILAR, Juan Bautista et al. (1999). Las emigraciones murcianas contemporáneas. Murcia: Universidad de Murcia. 